\title{
Kinetic of Anthocyanin Degradation in Roselle Extract Dried with Foaming Agent at Different Temperatures
}

\author{
Setia Budi Sasongko*, Mohamad Djaeni, Febiani Dwi Utari \\ Department of Chemical Engineering, Faculty of Engineering, Diponegoro University \\ Jl. Prof. Soedarto, Tembalang, Semarang 50275, Indonesia
}

Received: 30th June 2018; Revised: $6^{\text {th }}$ January 2019; Accepted: $7^{\text {th }}$ January 2019; Available online: $30^{h}$ April 2019; Published regularly: 1st August 2019

\begin{abstract}
This research studied the effect of drying temperature on the kinetic of degradation anthocyanin in roselle extract drying with foam under dehumidified air at temperatures ranging 40-60 ${ }^{\circ} \mathrm{C}$. During the drying process, the anthocyanin content in the roselle extract was observed every 20 minutes for 120 minutes. The data was used for estimating the kinetic parameters of anthocyanin degradation namely constant of anthocyanins degradation rate and reaction order. The kinetic parameters were estimated and fitted with experimental data at various drying condition. Result showed that the anthocyanins degradation closed to the second order reaction. Meanwhile, the constant of anthocyanins degradation rate at various drying temperatures followed Arhenius correlation. With the result, retention of anthocyanin during the drying can be well estimated for various drying time and temperature. Copyright $\mathbb{C}$ 2019 BCREC Group. All rights reserved
\end{abstract}

Keywords: Anthocyanin; Degradation kinetics; Drying; Foam Mat; Roselle

How to Cite: Sasongko, S.B., Djaeni, M., Utari, F.D. (2019). Kinetic of Anthocyanin Degradation in Roselle Extract Dried with Foaming Agent at Different Temperatures. Bulletin of Chemical Reaction Engineering \& Catalysis, 14 (2): 320-325 (doi:10.9767/bcrec.14.2.2875.320-325)

Permalink/DOI: https://doi.org/10.9767/bcrec.14.2.2875.320-325

\section{Introduction}

Roselle calyces (Hibiscus sabdariffa L.) contain red pigment, named anthocyanins usually used as the natural food colorant. Application of anthocyanins pigment is safer for consumer than that of synthetic dyes [1]. The anthocyanins in roselle calyces can be directly used for certain food such as jams [2], yogurt and cooked meat [3], while the roselle extract can be applied for the beverage [4].

The isolation of anthocynanin from roselle is not simple since it is unstable and easy to degrade (form undesirable brown color). The pro-

\footnotetext{
* Corresponding Author.

E-mail: sbudisas@live.undip.ac.id (S.B. Sasongko)

Telp: +62-24-7460058 Fax: +62-24-76480675
}

cess as well as storage condition such as light, $\mathrm{pH}$, temperature, and the presence of oxygen affected the stability of anthocyanins [5,6]. Drying process can be an option for rosella extract preservation. With the drying, the moisture content in roselle extract is removed. Therefore, microbial activity can be inhibited [7].

Currently, dried roselle extract was produced using microencapsulation technique using freeze dryer [4]. This technique was applied in jam and hard candy. The utilization of freeze dryer enhances the nutritional quality retention, but the process is costly [8]. The other optional process to produce the dried roselle extract is by combining foam mat drying and dehumidification system. Foam mat drying is a drying process with introduction of foaming 
agent in the wet material before drying. With the presence of foaming agent, the material forms a foam that can improve the surface area for drying process [9]. Hence, this process runs faster and the drying time can be shorter. Meanwhile in the dehumidification system, the moisture in air as drying medium was removed by an adsorbent. With lower humidity, the driving force for water transfer from product to air can be enhanced. As consequences, the process can be more effective, even at low drying temperature [7].

This research studied kinetic of degradation and structural changes of anthocyanins during the roselle extract drying with foaming agent under dehumidified air as drying medium. The process was conducted in different temperature. As a response, the anthocyanin content was observed every sampling time. The data was used for estimating kinetic parameters on anthocyanin degradation. The parameters can be used to predict the total of the anthocyanin retention. Moreover, the drying time and temperature can be selected to find the higher anthocyanin retention in dry roselle extract.

\section{Materials and Method}

\subsection{Materials}

Roselle calyces were purchased from the herbal market in Solo, Indonesia. The calyces were identified by The Hortus Botanicus Bogoriense Herbarium as the species Hibiscus sabdariffa $L$ (family Malvaceae). Distillation water was produced in Chemical Engineering Process Laboratorium and used within $24 \mathrm{~h}$ of production. Egg white was separated from the yolk to obtain the foaming agent. Glycerol Mono Stearate (GMS) as the foam stabilizer was from Sigma, Germany. Zeolite 3A was provided by Zeochem, Switzerland.

\subsection{Method}

This research was conducted in several steps that involved roselle extract pretreatment (roselle extraction and foam formulation), experiment of drying process, anthocyanins content analysis, and kinetic model development for anthocyanins degradation. The model was used for estimating the constant of degradation rate at various temperatures. Using the validated constant of degradation rate data, the Arrhenius model can be well developed.

\subsubsection{Roselle extraction}

The dried roselle calyces $(0.25 \mathrm{~mm}$ size $)$ were extracted using previous extraction meth- od [10]. One hundred grams of dried roselle calyces was extracted with $1000 \mathrm{~mL}$ of distilled water for 30 minutes. The extraction temperatures were controlled in temperature $50 \pm 2.88$ ${ }^{\circ} \mathrm{C}$. The mixture was filtered using vacuum filtration to obtain the red roselle extract.

\subsubsection{Foam formulation}

Foaming agents, egg white, was added in roselle extract to form the foam structure. Foaming stabilizer, Glycerol Mono Stearate (GMS) was added to avoid foam destruction. One hundred $\mathrm{ml}$ of roselle extract was mixed with Egg white (4 gram) and GMS (0.4 gram). After that, the solution was whipped using hand mixer at maximum speed for 3 minutes.

\subsubsection{Drying process}

The foam solution was then placed in round plate $(0.11 \mathrm{~m}$ diameter) for the drying process. The drying process was conducted in tray dryer with dehumidification process. The schematic overview of the dryer was listed in previous research [11]. Ambient air at around $31 \pm 0.25{ }^{\circ} \mathrm{C}$ and relative humidity $74 \pm 1.29 \%$ was passed in dehumidification process using zeolite $3 \mathrm{~A}$ (provided by Zeochem) to reduce the relative humidity up to $33 \pm 1.15 \%$. The air was then heated up to a drying temperature (supposed $40^{\circ} \mathrm{C}$ ). The hot air was used for roselle extract drying in tray dryer in linear velocity of 0.22 m.s. ${ }^{-1}$. The anthocyanins content was observed every 20 minutes for 120 minutes by $\mathrm{pH}$ differential method [12]. The process was repeated for different drying temperature $\left(50\right.$ and $\left.60^{\circ} \mathrm{C}\right)$.

2.2.4 Determination of total anthocyanins content by $\mathrm{pH}$ differential method

The $\mathrm{pH}$ differential method was used to observe the total anthocyanins content of fresh and dried roselle extract [12]. The method was conducted to measure the absorbance value of fresh and dried roselle extract at $\mathrm{pH} 1.0$ and $\mathrm{pH} 4.5$ at two wavelengths, $520 \mathrm{~nm}$ and 700 $\mathrm{nm}$. The $\mathrm{pH}$ changes can affect the color of anthocyanin pigments. At $\mathrm{pH} 1.0$ the colored oxonium form exists. Meanwhile, at $\mathrm{pH} 4.5$ the colorless hemiketal form exists. The absorbance was measured at $520 \mathrm{~nm}$ and $700 \mathrm{~nm}$ to correct the haze. The absorbance difference of the pigments at certain wavelength was proportional to the pigment concentration [13]. The absorbance was calculated using Equation 1 [12].

$$
A=\left(A_{520}-A_{700}\right)_{p H 1}-\left(A_{520}-A_{700}\right)_{p H 4.5}
$$


The absorbance value was used to calculate the total anthocyanins content $\left(A, \mathrm{mg} . \mathrm{L}^{-1}\right)$ as expressed in Equation 2 [12].

$$
A=\frac{D F \cdot M W \cdot 1000 \cdot A}{\varepsilon \cdot d}
$$

where, $D F$ is the dilution factor, MW is molecular weight of 449.2 g. $\mathrm{mol}^{-1}, A$ is the absorbance, $A_{520}$ and $A_{700}$ are absorbance at $520 \mathrm{~nm}$ and 700 $\mathrm{nm}$, respectively, $\varepsilon$ is the molar absorptivity (26900), and $d$ is the cuvette length $(1 \mathrm{~cm})$.

\subsubsection{Kinetic model of anthocyanins degrada-} tion

Two main anthocyanins compound contained in roselle calyces extracts were delphinidin-3-sambubioside (71.4\%) and cyanidin-3-sambubioside (26.6 \%) [14]. During the thermal processing, the anthocyanins degradation changed the structure of anthocyanins compound as illustrated in Figure 1 [15-17].

The kinetic $n^{\text {th }}$ model was used to describe the kinetic of degradation anthocyanins (Table 1 ). The statistical parameters namely $R^{2}$ and Root Mean Square Deviation (RMSD) were used to evaluate the kinetic model of anthocyanins degradation. The anthocyanins degradation can be expressed by the equations as listed in Table 1 , where $C_{A o}$ and $C_{A t}$ are total anthocyanins content of the roselle extract at time 0 and $t$, respectively, $k_{A}$ is the constant of anthocyanins degradation rate, and $n$ is reaction order.

Correlation between the constant of anthocyanins degradation rate and drying temperature can be expressed with Arrhenius as shown in Equation 5.

$$
\ln k_{A}=-\frac{E_{a}}{R} \frac{1}{T}+\ln k_{0}
$$

where, $E_{a}$ is the activation energy (J.mol-1), $R$ is the universal gas constant (8.314 J.mol $\left.{ }^{-1} \cdot \mathrm{K}^{-1}\right), T$ is absolute temperature $(\mathrm{K})$, and $k_{0}$ is frequency factor or Arrhenius constant $\left(\mathrm{min}^{-1}\right)$. The value of $E_{a}$ and $k_{0}$ are obtained by plotting the logarithm of constant of anthocyanins degradation rate $\left(k_{A}\right)$ versus the inverse temperature $(1 / T)$. This value can be used to predict the constant of anthocyanins degradation rate $\left(k_{A}\right)$ in higher drying temperatures.

\subsubsection{FTIR analysis}

FTIR spectrometer (Frontier FT-IR 96681 from Perkin Elmer, America) equipped with detector deuterated triglycine sulphate (DTGS), KBr as beam splitter, and connected to software Frontier's Spectrum 10 (Version 10.03.06). All FTIR spectra were recorded from 4000 to $400 \mathrm{~cm}^{-1}$ at a resolution of $4 \mathrm{~cm}^{-1}$. The sample measurements were replicated three times.

\subsubsection{Statistical analysis}

The kinetic parameters were evaluated by linear regression method and using Polymath Educational 6.0 Software. The validation of kinetic model was evaluated based $\mathrm{R}^{2}$ and Root Mean Square Deviation (RMSD). Kinetic model with $\mathrm{R}^{2}$ approximately 1.0 , and the lowest value of RMSD were selected to describe kinetic of anthocyanins degradation.

\section{Results and Discussion}

\subsection{Kinetic of Anthocyanins Degradation}

Environmental condition like $\mathrm{pH}$, light, oxygen, temperature, sugar, and ascorbic acid affected the stability of anthocyanins during processing $[5,6]$. The degradation of anthocyanins

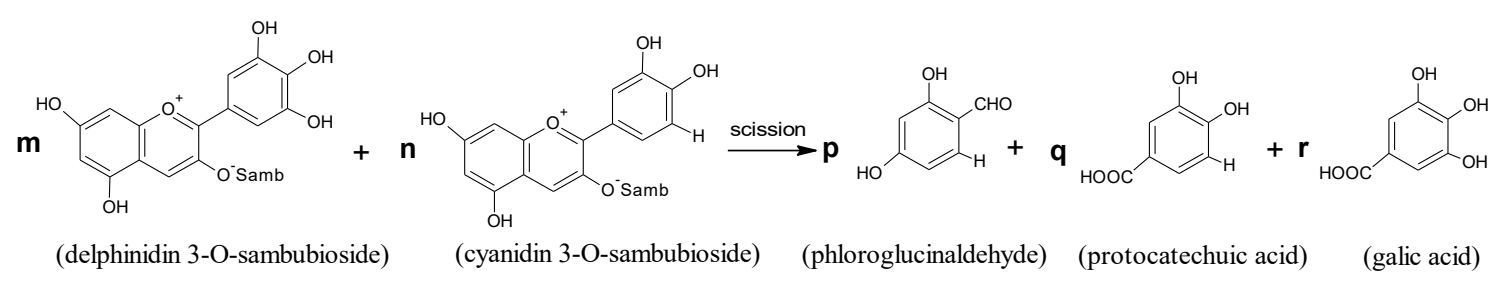

Figure 1. Chemical structures change of Delphinidin-3-sambubioside during thermal degradation [18]

\begin{tabular}{|c|c|c|c|}
\hline & Differential Equation & Linear Regression & \\
\hline Kinetics $n^{\text {th }}$ Order & $\frac{d C_{A}}{d t}=-k_{A} C_{A}^{n}$ & $C_{A 0}^{1-n}=C_{A t}^{1-n}+(n-1) k_{A} t$ & (4) \\
\hline
\end{tabular}

Table 1. Mathematical equation for kinetics order $n$ 
in various drying temperatures was shown in Figure 2. Based on the research, it can be found that in higher drying temperature and longer drying time degraded anthocyanins significantly. Based on quantitative analysis using $\mathrm{pH}$ differential method, roselle extract in the foam mat formulation contained total anthocyanins around $56.11 \mathrm{mg} . \mathrm{L}^{-1}$. At temperature of $60{ }^{\circ} \mathrm{C}$ the final anthocyanins content was 1.3 times lower than in temperature $40{ }^{\circ} \mathrm{C}$.

In this drying method, combination of foam mat drying and dehumidification system resulted several advantages: (1) decreasing the drying time by enlarging surface are for drying(foam mat) and enhancing the driving force for drying with lowering the relative humidity (dehumidification); (2) lowering the drying temperature $\left(40-60{ }^{\circ} \mathrm{C}\right)$ and retaining the nutrition or ingredients $[9,11,19]$. Compared to the previous study [20], roselle extract processing in high drying temperature $\left(70-90{ }^{\circ} \mathrm{C}\right)$ resulted higher constant of anthocyanins degradation rate than that of in low-medium temperatures (see Table 2). Thus, by lowering drying temperature, the anthocyanins compound in roselle extract can be potentially retained.

Kinetics of anthocyanins degradation $\left(k_{A}\right)$ during the drying process depends on temperature. The kinetic model was used to find the value of constant of anthocyanins degradation rate and the order of anthocyanins degradation at every operational temperatures. The results showed that the kinetic degradation of Anthocyanin closed to second order reaction as seen in Table 2. This was new finding since the usual kinetic model for anthocyanin degradation is the kinetic first model such as blood orange juice [14,15], sour cherry paste [21], red currant juice [22]. Perhaps, the different pre- treatment by introduction of foaming agent as implemented in this research resulted the different kinetic model of anthocyanin degradation. The kinetic data were then used for estimating Arrhenius parameters namely activation energy $\left(E_{A}\right)$ and the value of $k_{0}$ (as expressed in Equation 5). Using the validated Arrhenius parameters, the constant of anthocyanins degradation rate can be estimated for both interpolated and extrapolated temperature (40 and $70{ }^{\circ} \mathrm{C}$ ). Furthermore, the anthocyanin retention during the drying time at the extrapolated temperature can be predicted. The anthocyanin retention estimated by the models was then compared with experiment data at the same drying time [11] and temperature. The result as depicted in Table 3 indicated that the model can fit with experiment data with the deviation rounding 4.0-5.0\%.

\subsection{Anthocyanins Structure Changes}

The thermal degradation caused the structural changes of anthocyanins [19-21]. The cyanidin-3-sambubioside converted to the phenolic aldehyde (phloroglucinaldehyde) and protocate-

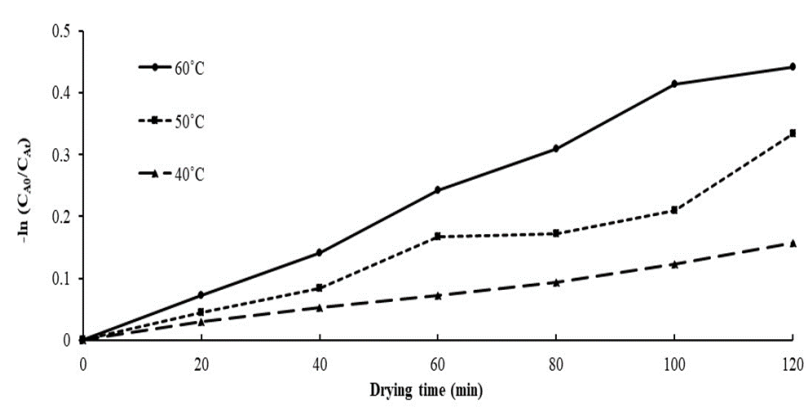

Figure 2. Anthocyanins degradation during foam mat drying of roselle extract

Table 2. Kinetics of second order for anthocyanins degradation during roselle extract drying under various temperatures

\begin{tabular}{ccccccc}
\hline Kinetics $n^{\text {th }}$ Order & Temperature $\left({ }^{\circ} \mathrm{C}\right)$ & $k_{A} \times 10^{-5}$ & $\mathrm{R}^{2}$ & $\mathrm{RMSD}$ & $E_{A}\left(\mathrm{~kJ} . \mathrm{mol}^{-1}\right)$ & $k_{0}\left(\times 10^{4}\right)$ \\
\hline 2.00 & 40 & 2.39 & 0.99 & 0.15 & & \\
2.00 & 50 & 5.04 & 0.97 & 0.39 & 55.41 & 16.5 \\
2.00 & 60 & 8.56 & 0.99 & 0.42 & & \\
\hline
\end{tabular}

Table 3. Validation kinetic model of antocyanin retention

\begin{tabular}{ccccc}
\hline \multirow{2}{*}{$T\left({ }^{\circ} \mathrm{C}\right)$} & Drying time $(\mathrm{min})$ & $\begin{array}{c}\text { Anthocyanin retention } \\
\text { experiment }(\%)\end{array}$ & \multicolumn{2}{c}{ Second order Kinetic } \\
\cline { 3 - 5 } & 145.3 & 86.90 & 83.31 & Anthocyanin retention \\
\hline 40 & 73.9 & 63.59 & 60.28 & 5.12 \\
\hline
\end{tabular}


chuic acid (Figure 1). Whereas, the Delphinidin-3-sambubioside changed to phenolic aldehyde (phloroglucinaldehyde) and phenolic acids namely gallic acid, as presented in Figure 2 [23]. The anthocyanin degradation increased for longer thermal processing [18].

There were some structural changes based on FTIR analysis (Figure 3). The peak of dried extract was not as high as the peak of fresh extract. The $b$ and c peak can be seen in the dried product. While in the fresh extract it did not appear. The $b$ and $c$ peak indicated the peak of $\mathrm{C}=\mathrm{O}$ (aldehyde) and $=\mathrm{C}-\mathrm{H}$ (aldehyde) which form the structure of phenolic aldehyde or phloroglucinaldehyde (see Table 4). The degradation product (gallic acid, protocatechuic acid, and phloroglucinaldehyde) appeared in dried roselle extract as the effect of thermal degradation of anthocyanins [18].

\section{Conclusions}

Roselle extract with foam formulation contains total anthocyanins around 56.11 mg.L $\mathrm{L}^{-1}$. In higher drying temperature and longer drying time, the anthocyanin content degraded significantly. Combination of foam mat drying and dehumidification process can shorten the drying process which can can retain the anthocyanin content. The kinetics of anthocyanins degradation closed to the second order kinetic mod-

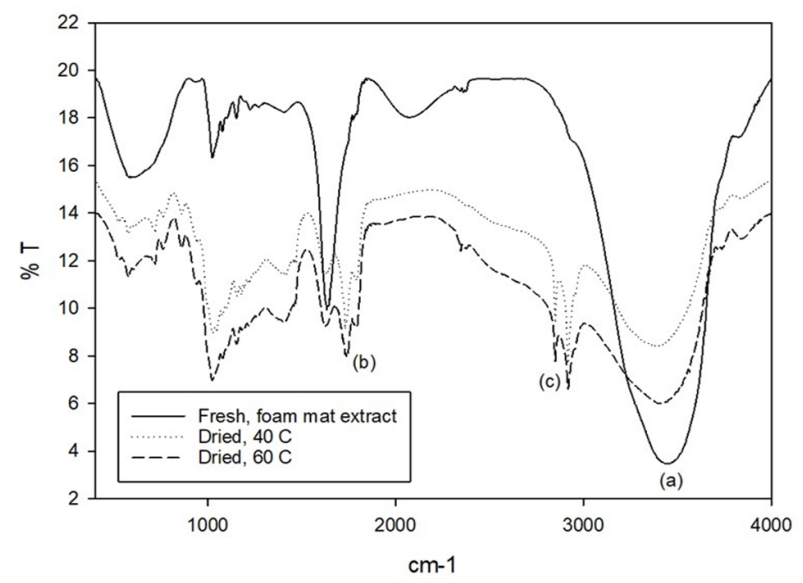

Figure 3. FTIR spectra of fresh and dried roselle extract at frequency of $400-4000 \mathrm{~cm}^{-1}$ el. For different temperature, the constant of anthocyanins degradation rate can be predicted using Arrhenius correlation with activation energy of $55.41 \mathrm{~kJ} . \mathrm{mol}^{-1}$ and constant rate $\left(k_{0}\right)$ of $16.5 \times 10^{4}$. The parameters were also validated for estimating anthocyanin degradation at extrapolated temperature.

\section{References}

[1] Ashaye, O.A., Deleke, T.O. (2009). Quality Attributes of Stored Roselle Jam. International Food Research Journal, 16: 363-371.

[2] Henry, N., Badrie, N. (2007). Utilization of Sorrel/Roselle (Hibiscus Sabdariffa L.) Nectar in Stirred Yoghurts: Physicochemical and Sensory Quality. Journal of Food Technology, 5(1): 55-61.

[3] Bozkurt, H., Belibağli, K. (2009). Use of Rosemary and Hibiscus Sabdariffa in Production of Kavurma, A Cooked Meat Product. Journal of the Science of Food and Agriculture, 89(7): 1168-1173.

[4] Selim, K.A., Khalil, K.E., Abdel-Bary, M.S., Abdel-Azeim, N.A. (2008). Extraction, Encapsulation and Utilization of Red Pigments from Roselle (Hibiscus Sabdariffa L.) as Natural Food Colourants. Alexandria Journal for Food Science and Technology: 7-20.

[5] Tsai, P., Huang, H. (2004). Effect of Polymerization on the Antioxidant Capacity of Anthocyanins in Roselle. Food Research International. 37(4): 313-318.

[6] Youssef, M.A., El-kady, A.A., Nagy, K.S. (2015). Effect of Engineering Treatments on Extraction of Roselle Juice (Karkdah). Middle East Journal of Agriculture Research, 4(4): 697-706.

[7] Djaeni, M., van Asselt, C.J., Bartels, P.V., Sanders, J.P.M., van Straten, G., van Boxtel, A.J. (2011). Low Temperature Drying with Air Dehumidified by Zeolite for Food Products: Energy Efficiency Aspect Analysis. International Journal of Food Engineering, 7(6): Article 4.

[8] Agnieszka, C., Lenart, A. (2011). FreezeDrying - Application in Food Processing and Biotechnology - A Review. Pol. J. Food Nutr. Sci, 61(3): 165-171.

Table 4. FTIR absorptions of several functional groups

\begin{tabular}{ccc}
\hline Peak number & Wavelength $\left(\mathrm{cm}^{-1}\right)$ & Compound \\
\hline $\mathrm{a}$ & 3454 & OH \\
$\mathrm{b}$ & 1716 & $\mathrm{C}=\mathrm{O}$ (aldehyde) \\
$\mathrm{c}$ & 2850,2918 & $=\mathrm{C}-\mathrm{H}$ (aldehyde) \\
\hline
\end{tabular}


[9] Ratti, C., Kudra, T. (2006). Drying of Foamed Biological Materials : Opportunities and Challenges Drying of Foamed Biological Materials: Opportunities. Drying Technology, 24: 1101-1108.

[10] Chumsri, P., Sirichote, A., Itharat, A. (2008). Studies on the Optimum Conditions for the Extraction and Concentration of Roselle (Hibiscus Sabdariffa Linn.) Extract. Songklanakarin Journal of Science and Technology, 30(SUPPL. 1): 133-139.

[11] Djaeni, M., Kumoro, A.C., Sasongko, S.B., Dwi, F. (2018). Drying Rate and Product Quality Evaluation of Roselle (Hibiscus sabdariffa L.) Calyces Extract Dried with Foaming Agent under Different Temperatures. International Journal of Food Science. 2018: Article ID 9243549.

[12] Anuar, N., Mohd Adnan, A.F., Saat, N., Aziz, N., Mat Taha, R. (2013). Optimization of Extraction Parameters by Using Response Surface Methodology, Purification, and Identification of Anthocyanin Pigments in Melastoma Malabathricum Fruit. The Scientific World Journal. 2013: Article ID 810547.

[13] Lee, J., Wrolstad, R.E., Durst, R. (2005). Determination of Total Monomeric Anthocyanin Pigment Content of Fruit Juices, Beverages, Natural Colorants, and Wines by the pH Differential Method: Collaborative Study. Journal of AOAC International. 88(5): 1269-1278.

[14] Wong, P., Yusof, S., Ghazali, H.M., Che Man, Y.B. (2002). Physico-chemical Characteristics of Roselle (Hibiscus sabdariffa L.). Nutrition \& Food Science, 32(2): 68-73.

[15] Kern, M., Fridrich, D., Reichert, J., Skrbek, S., Nussher, A., Hofem, S., Marke, D. (2007). Limited Stability in Cell Culture Medium and Hydrogen Peroxide Formation Affect the Growth Inhibitory Properties of Delphinidin and Its Degradation Product Gallic Acid. Molecular Nutrition and Food Research, 51(9): 1163-1172.
[16] Sinela, A.M., Mertz, C., Achir, N., Rawat, N., Vidot, K., Fulcrand, H., Dornier, M. (2017). Exploration of Reaction Mechanisms of Anthocyanin Degradation in a Roselle Extract through Kinetic Studies on Formulated Model Media. Food Chemistry, 235: 67-75.

[17] Sun, J., Bai, W., Zhang, Y., Liao, X., Hu, X. (2011). Identification of Degradation Pathways and Products of Cyanidin-3-Sophoroside Exposed to Pulsed Electric Field. Food Chemistry, 126(3): 1203-1210.

[18] Sinela, A., Rawat, N., Mertz, C., Achir, N., Fulcrand, H., Dornier, M. (2017). Anthocyanins Degradation during Storage of Hibiscus Sabdariffa Extract and Evolution of Its Degradation Products. Food Chemistry, 214: 234241.

[19] Djaeni, M., Sasongko, S.B., Prasetyaningrum A., Jin, X., Van Boxtel, A.J. (2012). Carrageenan Drying with Dehumidified Air: Drying Characteristics and Product Quality. International Journal of Food Engineering. 8(3): Article 32 .

[20] Cao, S. qian, Liu, L., Pan, S. yi. (2011). Thermal Degradation Kinetics of Anthocyanins and Visual Color of Blood Orange Juice. Agricultural Sciences in China, 10(12): 1992-1997.

[21] Zori, Z., Dragovi-Uzelac, V., Pedisi, S., Kurtanjek, Z., Garofuli, I.E. (2014). Kinetics of the Degradation of Anthocyanins, Phenolic Acids and Flavonols during Heat Treatments of Freeze-Dried Sour Cherry Marasca Paste. Food Technol. Biotechnol, 52(1): 101-108.

[22] Kopjar, M., Piližota, V., Šubari, D., Babi, J. (2009). Prevention of Thermal Degradation of Red Currant Juice Anthocyanins by Phenolic Compounds Addition. Journal of Food Science, 1(1): 24-30.

[23] Hrazdina, G., Borzell, A.J. (1971). Xanthylium Derivatives in Grape Extracts. Phytochemistry, 10(9): 2211-2213. 